\title{
WOULD THE BORDA COUNT HAVE AVOIDED THE CIVIL WAR?
}

\section{Alexander Tabarrok and Lee Spector}

\begin{abstract}
The election of 1860 was one of the most important and contentious elections in US history. It was also one of the most interesting. Four candidates from three different parties battled for the presidency and all four received a significant number of votes. We ask whether Lincoln's victory was sound, or was it due to a fluke in the electoral system? Did a Lincoln win plausibly represent the will of the voters or would a different voting system have represented their preferences more accurately? Would the outcome have been the same had one or more of the candidates dropped out of the race? These and other questions are answered using new graphical techniques which let us assess voter preferences more accurately. Using these techniques, we are able to show, in a single figure, the outcome of every positional voting system, as well as all possible approval voting outcomes. By comparing the outcome under plurality rule to the outcomes which would have occurred under other voting systems, we conclude that Stephen Douglas, not Lincoln, was plausibly the candidate who best represented the preferences of the voters.
\end{abstract}

KEY WORDS • elections $\bullet$ social choice $\bullet$ US civil war $\bullet$ voting

The election of 1860 was one of the most important and contentious elections in US history. It was also one of the most interesting. Four candidates from three different parties battled for the presidency and all four received significant numbers of votes. Abraham Lincoln won with a majority of electoral college votes but only a slim plurality of the popular vote. Stephen Douglas had almost as many popular votes as John Bell and John Breckinridge combined yet had only 12 electoral votes as compared to the combined Bell-Breckinridge total of 111. These peculiarities raise a host of questions. Was Lincoln's victory sound or was it due to a fluke in the electoral system? Did a Lincoln win plausibly represent the will of the voters or would a different voting system have represented their preferences more accurately? What would have happened had voting systems other than plurality rule been used? Who would have won if one of the candidates had dropped out of the race?

Of course we can never answer counterfactual questions with certainty.

We would like to thank the editor and several anonymous referees for useful comments. 
Had the voting system been different, candidate and party strategies would have been different. Lincoln could easily have lost the Republican convention to Seward, for example, and history would have changed. In truth, however, we ask counterfactual questions not to understand what did not happen but to understand better what did. A naive analyst might infer from Lincoln's victory that Lincoln was the predominant choice of the voters. Our results cast considerable doubt on this inference. Douglas, not Lincoln, would have won the election of 1860 under many voting systems other than plurality rule. Had Lincoln and Douglas faced each other one on one in the 1860 elections as they did in the debates of 1858 , for example, Douglas would have won. Indeed, under some voting systems it is quite possible that the compromise candidate John Bell might have won the election. Understanding this tells us much about the relationship between Lincoln's victory and the preferences of US voters. Lincoln's victory cannot be taken as prima facie evidence for strong Lincoln support among the electorate.

By examining what would have happened under alternative systems we gain perspective on the extent to which an outcome was determined by preference and the extent to which it was determined by the voting system. A single electoral outcome provides only limited information about the underlying support for a candidate. A candidate who wins an election may in a real sense be less preferred than a losing candidate, and a candidate who wins one election with 60 percent of the vote may be less preferred than another candidate who wins a different election with 35 percent of the vote. Understanding the true strength of a candidate may help us better understand post-election politics. ${ }^{1}$ From the opposite perspective, examining what would have happened under alternative systems helps us understand how voting systems influence outcomes.

A key purpose of our paper is to demonstrate for a wide audience some of the advantages of Saari's (1994) geometric approach to voting theory. We use the election of 1860 as an important but accessible example to illustrate the new techniques. The techniques can easily be applied to other elections (Tabarrok, 1997, 1998). In the first section we present a compact and less technical explanation of some important results in voting theory, due to Saari (1994). The second section explores the election of 1860 in more detail, and in the third section we apply the theory.

Our approach is most closely related to that of Riker (1982), who also examines the 1860 election. Riker, however, looks at only two of the infinitely many positional voting systems (plurality rule and the Borda

1. Tabarrok (1997), for example, shows that in 1992 Clinton was a surprisingly strong candidate. Clinton would have won under any positional voting system despite the fact that he received less than a majority of votes in the actual election. Brams and Merrill (1994) also analyze the 1992 election. 
Count) and he finds only one possible approval vote outcome. In contrast, we find the outcome for every positional vote system. We also find every possible approval vote outcome. In addition, we analyze what would have happened had one or more of the candidates dropped out of the election. We use Riker's estimates of the voter profile as well as the mean estimate of a group of historians to 'calibrate' our calculations.

\section{The Theory of Voting}

In our analysis we will focus on three types of voting systems. We will look at the class of positional voting systems, pairwise voting, and approval voting. Despite its importance to the US electoral system, we will for the most part ignore the electoral college in order to focus on results of more general applicability. An appendix discusses the role of the electoral college in the 1860 election.

\section{Theory of Positional Voting}

Let there be $n$ candidates in an election and assume that each voter can rank the $n$ candidates from most to least favored. A positional system assigns points to the voter's list, with more favored candidates receiving more (or at least not fewer) points than less favored candidates. Plurality rule is a particularly simple positional system; it assigns one point to a voter's top-ranked candidate and zero points to every other candidate. The simplicity of plurality rule comes at a price, however; plurality rule throws away valuable information about voter rankings. Plurality rule, for example, cannot distinguish between the rankings $a>b>c$ and $a>c>b$, even though these differences may sometimes be important. Let 10,001 voters rank the candidates $a>b>c$ and 10,000 rank them $b>c>a$. Using plurality rule $a$ wins, even though $b$ is in many ways a better choice. Candidates $a$ and $b$ have virtually the same number of first-place votes, but candidate $a$ is ranked last by 10,000 voters while no voter ranks $b$ last. If the 10,001 voters had instead had the ranking $a>c>b$ then a win by $a$ would have been uncontroversial. Thus for the choice to be intelligent, a voting system must be able to discriminate among the different voter rankings. It is this goal which motivates other positional voting systems.

The Borda Count is a positional voting system devised by the 18thcentury French mathematician, Jean Charles Borda. It assigns $(n-1)$ points to a voter's top-ranked candidate, $(n-2)$ points to a second-ranked candidate and $(n-i)$ points to an $i$ 'th ranked candidate. Using the Borda Count, $b$ wins when the 10,001 voters have ranking $a>b>c$ and $a$ wins when they have the ranking $a>c>b$. 
If we simplify by assuming that $n=3$, we can write the plurality rule system as $\{1,0,0\}$ and the Borda Count as $\{2,1,0\}$. Plurality rule and the Borda Count are only two of infinitely many positional voting systems. Another voting system - this one without a particular name - assigns 20 points to the top-ranked candidate, six points to the second-ranked candidate and three points to the last-ranked candidate, or $\{20,6,3\} .^{2}$ Suppose we modify the $\{20,6,3\}$ voting system by subtracting three points from each point assignment to get $\{17,3,0\}$, this will not change the final ranking of candidates. If a candidate wins the election under $(20,6,3)$ he/she will also win under $(17,3,0)$ and similarly for the second- and third-placed candidates. The $\{20,6,3\}$ and $\{17,3,0\}$ vote systems are therefore equivalent. Now divide each point assignment by the sum of all points to get $\left(\frac{17}{20}, \frac{3}{20}, \frac{0}{20}\right)$. This new vote system is also equivalent to $\{20,6,3\}$. By repeating the two processes just described we can change any positional voting system into a standardized positional system denoted $\{1-s, s, 0\}$, where $s \in\left[0, \frac{1}{2}\right]$. Every positional system is thus associated with a single number, $s .{ }^{3}$

A voter may rank $n$ candidates in any one of $n$ ! possible ways. If the candidates are $a, b, c$, for example, then a voter could rank them: (1) $a b c$, (2) $a c b$, (3) $c a b$, (4) $c b a$, (5) $b c a$, or (6) $b a c$, where precedence in the list indicates preference. (The numbering of these rankings is arbitrary but later we use the numbers as shorthand.) Note that under vote system $s$ a voter with ranking $a b c$ gives $(1-s)$ points to $a, s$ points to $b$ and 0 points to $c$, while a voter with ranking $c b a$ gives 0 points to $a, s$ points to alternative $b$, and $(1-s)$ points to alternative $c$. We can place all of this information in a vote matrix (Figure 1).

The vote matrix can be read in two ways. Reading down a particular column, we see the number of points given to each candidate from a voter with the ranking indicated by that column. A voter of type $c b a$, for example, gives points of $0, s$, and $(1-s)$ to candidates $a, b$, and $c$ respectively. Reading across the rows we see where a candidate's votes come from. Candidate $b$, for example, gets $s$ votes from each voter of type $a b c$ or $c b a$, zero points from each voter of type $a c b$ or $c a b$ and $(1-s)$ points from each voter of type $b c a$ or $b a c$.

We write the proportion of voters with ranking $a b c$ as $p_{1}$, the proportion of voters with ranking $a c b$ as $p_{2}$, and so forth up until $p_{6}$. We call the set

2. Positional voting systems other than plurality rule and the Borda Count are sometimes used in practice. The Baseball Writers Association of America, for example, asks two members in each city with a major league baseball team to rank their top ten players. A writer's top-ranked player is assigned 14 points, the second-ranked player nine points, the third-ranked player eight points and so forth, all the way down to the last-ranked player who is assigned one point.

3. This characterization of positional voting systems and the graphical interpretation given below are due to Saari (1994). 


\begin{tabular}{|c|c|c|c|c|c|c|}
\hline & $a b c$ & $a c b$ & $c a b$ & $c b a$ & $b c a$ & $b a c$ \\
\hline$a$ & $1-s$ & $1-s$ & $s$ & 0 & 0 & $s$ \\
\hline$b$ & $s$ & 0 & 0 & $s$ & $1-s$ & $1-s$ \\
\hline$c$ & 0 & $s$ & $1-s$ & $1-s$ & $s$ & 0 \\
\hline
\end{tabular}

Figure 1. Standardized Positional Vote Matrix

$\left\{p_{1}, p_{2}, p_{3}, p_{4}, p_{5}, p_{6}\right\}$ a voter profile. We now have all the information we need to find the outcome of any election using a positional voting system. Reading the vote matrix across row $a$, for example, we see that candidate $a$ receives

$$
p_{1} *(1-s)+p_{2} *(1-s)+p_{3} * s+p_{4} * 0+p_{5} * 0+p_{6} * s \text { votes. }
$$

The general positional voting system can therefore be written as:

$$
\left(\begin{array}{cccccc}
1-s 1-s & s & 0 & 0 & s \\
s & 0 & 0 & s & 1-s 1-s \\
0 & s & 1-s 1-s & s & 0
\end{array}\right)\left(\begin{array}{c}
p_{1} \\
p_{2} \\
p_{3} \\
p_{4} \\
p_{5} \\
p_{6}
\end{array}\right)=\left(\begin{array}{c}
p_{1}+p_{2}+\left(-p_{1}-p_{2}+p_{3}+p_{6}\right) * s \\
p_{6}+p_{5}+\left(p_{4}-p_{5}+p_{1}-p_{6}\right) * s \\
p_{3}+p_{4}+\left(p_{2}-p_{3}-p_{4}+p_{5}\right) * s
\end{array}\right)
$$

The equations on the right-hand side of the above matrix (Equations 1) determine the vote share for $a, b$ and $c$, respectively. These equations are all linear functions of $s$, which makes them easy to plot on a graph.

By varying $s$ from 0 to $\frac{1}{2}$ we can find, for a given voter profile, what the outcome will be for every possible positional vote system. All three vote shares can be shown on a single diagram. Let the vote share of candidate $a$ be given on the $x$-axis and the vote share of candidate $b$ on the $y$-axis. Since vote shares must add up to one, the share of $c$ is found implicitly by the distance from the line $a+b=1$ to the point $(a, b)$ along an orthogonal.

Consider, for example, the profile $\left\{p_{1}, p_{2}, p_{3}, p_{4}, p_{5}, p_{6}\right\}=\{0, .419,0, .258$, $.322,0\}$ where .419 , for example, indicates that 41.9 percent of the voters are of Type 2. We plot the positional vote outcome for every vote system for this profile of voters in Figure 2. Following Saari (1994), we call the line of vote outcomes the procedure line.

In Figure 2 there are six regions labeled 1 to 6 . These six regions correspond to the six possible rankings of candidates: (1) $a b c$, (2) $a c b$, (3) $c a b$, (4) $c b a$, (5) $b c a$, and (6) bac. The center point, where the lines dividing the regions meet, is the outcome where all three candidates are tied for first 


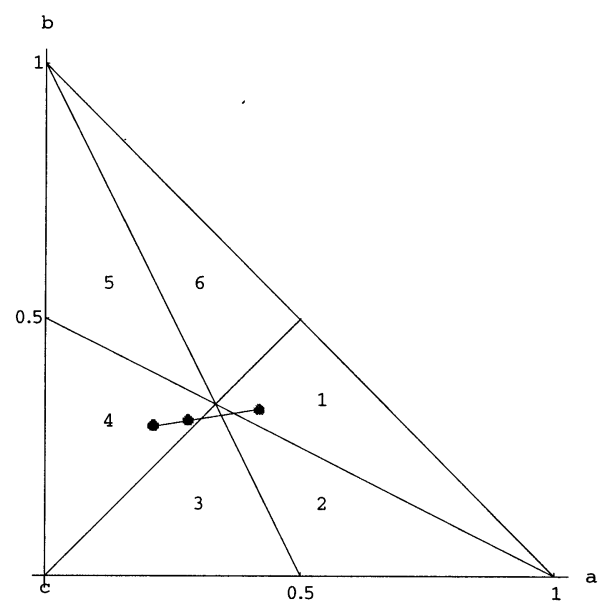

Figure 2. All Positional Vote Outcomes for the Profile $(0, .419,0, .258, .322 .0)$. (The plurality rule outcome is on the right, the Borda Count outcome is in the middle and the anti-plurality rule outcome on the left.)

place. ${ }^{4}$ The point furthest to the right along the graphed procedure line is the plurality rule outcome. The point furthest to the left is the 'antiplurality' rule outcome. Anti-plurality rule assigns one point to each of a voter's top-two ranked candidates (this vote system is called 'anti-plurality rule' because it is equivalent to giving a single negative vote to the lastranked candidate and having the candidate with the fewest negative votes win). In between the plurality and anti-plurality rule lie the outcomes for all other positional vote systems. The outcome indicated by the middle point, for example, is the Borda Count, which is associated with $s=\frac{1}{3} .5$ The procedure line in Figure 2 tells us that for the profile of voters $\{0,419,0, .258,322,0\}$ there are seven possible ordinal rankings (four strict rankings and three rankings involving ties where the procedure line crosses one of the lines separating the regions).

4. The three lines separating the regions are lines of equal vote shares. Along the 45-degree line from the origin, for example, candidates $a$ and $b$ have an equal share of votes. At the origin $a$ and $b$ each have 0 percent of the votes and $c$ has 100 percent. Moving along the 45-degree line, $a$ and $b$ increase their vote shares at the expense of $c$. At the point furthest to the right along the 45 -degree line, therefore, $a$ and $b$ each receive 50 percent of the votes and $c$ receives zero. Points below the 45 -degree line are areas where $a>b$, and vice versa for points above the 45-degree line. Similar reasoning using the other two lines can be used to deduce the rankings of each region from the graph alone.

5. Plurality rule corresponds to $s=0$, the Borda Count to $s=\frac{1}{3}$ and anti-plurality rule to $s=\frac{1}{2}$. Since $\frac{1}{3}$ is closer to $\frac{1}{2}$ than to 0 the Borda Count outcome is closer on the procedure line to the anti-plurality rule outcome than to the plurality rule outcome. This makes identifying each outcome simple. 
The linearity of equations (1) generalizes to higher dimensions. Two points serve to define a line, so we can rewrite equations (1) in implicit form as

$$
(1-2 s)\left(W_{0} \cdot P\right)+2 s\left(W_{\frac{1}{2}} \cdot P\right)
$$

where $W_{0}$ is the plurality rule vote matrix (i.e. the standardized positional vote matrix when $s=0), W_{\frac{1}{2}}$ is the anti-plurality rule matrix, $P$ is the voter profile and $s \in\left[0, \frac{1}{2}\right]{ }^{6}$ Although any two points will define the procedure line it's convenient to choose vertices, which is why we have used the plurality and anti-plurality rule endpoints. With four candidates the set of voting outcomes will form a plane in the 3-simplex. A plane can be defined by three points, and we again choose vertices, so the outcome can be written

$$
\left(1-s_{2}-s_{3}\right)\left(W_{\{0,0\}} \cdot P\right)+s_{2}\left(W_{\left\{\frac{12}{2}, 0\right\}} \cdot P\right)+s_{3}\left(W_{\left\{\frac{12}{3}+\frac{1}{3}\right.} \cdot P\right)
$$

where $W_{\left\{s_{2}, s_{3}\right\}}$ defines a standardized vote matrix and

$$
1 \geq 1-s_{2}-s_{3} \geq s_{2} \geq s_{3} \geq 0 .
$$

Figure 3 presents two views of the space of possible outcomes where the candidates are labeled $L, D, R, B$. Outcome space is the 3 -simplex bounded by $\{1,0,0\},\{0,1,0\},\} 0,0,1\}$ and the fourth candidate's share is given by $1-L$ $-D-R$. The 'lines' separating the regions are now planes. In the figure we have labeled some, but not all, of the outcome regions.
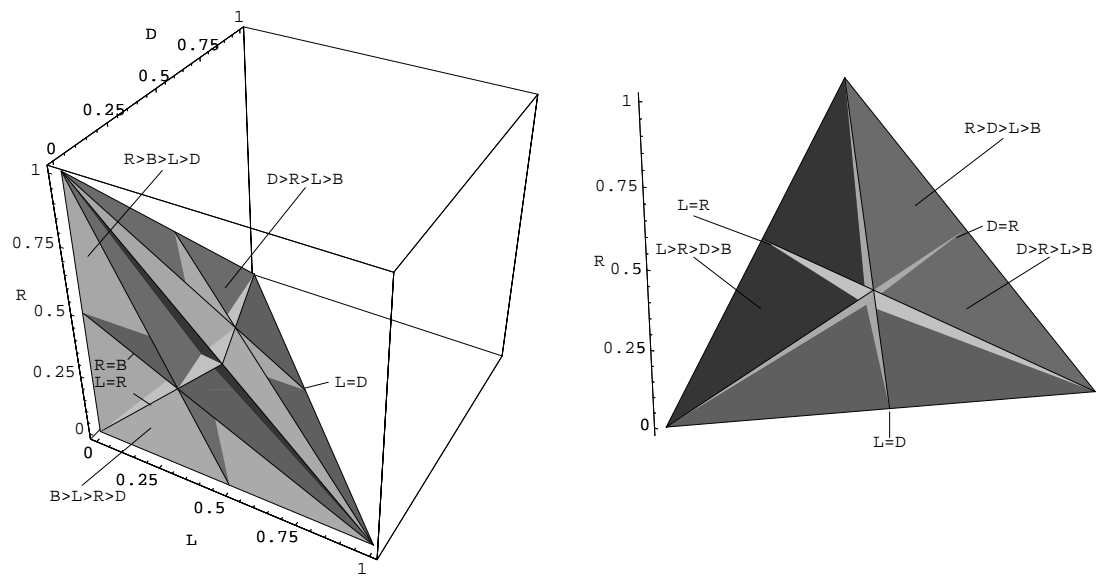

Figure 3. Two Views of the Space of all Possible Positional Vote Outcomes

6. Consider two points $x$ and $y$. The line joining these points can be written implicitly as $t x+(1-t) y$ where $t \in[0,1]$. Equation (2) comes from noting that $\left(W_{0} . P\right)$ is the vote outcome (point) given plurality rule, $\left(W_{\frac{1}{2}} \cdot P\right)$ is the outcome given anti-plurality rule and $s=t / 2$ so $t=2 s$. 


\section{Theory of Pairwise Voting}

In pairwise voting every candidate is matched against every other candidate and the winner of each contest is decided by majority rule. As is well known, pairwise majority voting can be indeterminate. The pairwise vote matrix (Figure 4) is written:

\begin{tabular}{|c|c|c|c|c|c|c|}
\hline & $a b c$ & $a c b$ & $c a b$ & $c b a$ & $b c a$ & $b a c$ \\
\hline$a v \cdot b$ & 1 & 1 & 1 & -1 & -1 & -1 \\
\hline$b v \cdot c$ & 1 & -1 & -1 & -1 & 1 & 1 \\
\hline$c v \cdot a$ & -1 & -1 & 1 & 1 & 1 & -1 \\
\hline
\end{tabular}

Figure 4. The Pairwise Vote Matrix

Reading across the rows the matrix indicates that in the pairwise election $a$ v. $b$ voters of types 1,2 , and 3 cast votes for $a$ while voters of types 4,5 and 6 cast their votes against $a$ (for $b$ ). If the sum of the votes is positive $a$ wins, if the sum of the votes is negative $b$ wins. An $a v$. $b$ outcome of $\frac{1}{3}$, for example, indicates that $a$ received a one-third greater share of votes than $b$. Thus $a$ must have received two-thirds of the vote to $b$ 's one-third. Reading down the columns indicates that a voter of type $a b c$ will vote for $a$ in an election of $a v . b, b$ in the election of $b v . c$ and $a$ (against $c$ ) in the election $c v$. $a$. The vote system can then be written:

$$
\left(\begin{array}{cccccc}
1 & 1 & 1 & -1 & -1 & -1 \\
1 & -1 & -1 & -1 & 1 & 1 \\
-1 & -1 & 1 & 1 & 1 & -1
\end{array}\right)\left(\begin{array}{c}
p_{1} \\
p_{2} \\
p_{3} \\
p_{4} \\
p_{5} \\
p_{6}
\end{array}\right)=\left(\begin{array}{c}
p_{1}+p_{2}+p_{3}-p_{4}-p_{5}-p_{6} \\
p_{1}-p_{2}-p_{3}-p_{4}+p_{5}+p_{6} \\
-p_{1}-p_{2}+p_{3}+p_{4}+p_{5}-p_{6}
\end{array}\right)
$$

Extending the system to handle more candidates is trivial.

\section{Theory of Approval Voting}

In a remarkable group of papers in the late 1970s, five sets of researchers independently invented a new form of voting now known as Approval Voting (AV). (Steven J. Brams and Peter C. Fishburn have done the most to analyze and popularize this form of voting; see Brams and Fishburn (1983) for an overview.) Approval voting lets a voter vote for as many 
different candidates as he/she 'approves'. If there are five candidates, for example, the voter can vote for one, two, three, four or even all five candidates. (Giving one vote to every candidate is equivalent to not voting so we would not expect to see this happen very often.)

An important feature of approval voting is that a voter profile is not sufficient to determine a unique election outcome. Consider two voters, Joe and Linda, who both have the ranking $a b c$. Joe could vote for his toptwo ranked candidates $a$ and $b$ while Linda could vote for $a$ only. The decision to cast a top-two ballot or a top-one ballot will depend on preferences (and also on beliefs about what other voters will do). If Joe greatly prefers either $a$ or $b$ to $c$ he is likely to cast a top-two ballot while Linda may cast a top-one ballot if she greatly prefers $a$ to either $b$ or $c$. A single profile is thus associated with many different outcomes, depending on the proportion of each type of voter who casts a top-two or top-one ballot. Let the proportion of Type 1 voters casting top-two ballots be $r_{1}$, the proportion of Type 2 voters casting such ballots $r_{2}$, and so forth. We are interested in finding the $\mathrm{AV}$ outcome for every possible combination of $\left\{r_{1}, r_{2}, r_{3}, \ldots r_{n !-1}, r_{n !}\right\}$ where the $r$ 's are independent and each $r_{i} \in[0,1]$.

Before we find the AV outcome for every combination of $\left\{r_{1}, r_{2}\right.$, $\left.r_{3}, \ldots r_{n !-1}, r_{n !}\right\}$ it will be useful to examine a simpler problem. Suppose the proportion of voters casting top-two ballots is the same for every type of voter. Call this proportion $r$. Assume that $r=0$, then every voter casts a top-one ballot and approval voting gives the same outcome as plurality rule. Now assume that $r=1$, then every voter casts a top-two ballot and approval voting gives the same outcome as the anti-plurality rule (given three candidates). More generally, approval voting with proportion $r$ gives the same outcome as the positional voting system $s=\frac{r}{2}$. The procedure line is thus a subset of the total set of possible approval vote outcomes. It follows that if a ranking occurs under some positional vote system then it also occurs under approval voting. Geometrically, if the procedure line crosses a boundary then the convex hull of AV outcomes also crosses that boundary. This leads to the following theorem (Theorem One of Saari and Van Newenhizen, 1988a):

Theorem 1. A necessary (but not sufficient) condition for all the AV outcomes to be within one ranking region is that every positional vote system gives the same ranking.

The bracketed qualifier is the most important aspect of Theorem 1. It is quite possible that every positional vote system ranks the candidate in the same way, yet multiple rankings are possible under AV. Indeed despite the fact that every positional vote system ranks the candidate the same way, AV may be completely indeterminate, i.e. AV may allow every ranking as a possible outcome. We discuss this possibility further below. 
Referring again to Figure 2, we now know that each of the seven rankings which occur under different positional vote systems is also a possible outcome under approval voting. But the procedure line is only a subset of the total approval vote outcomes. To find the other possible approval vote outcomes we need to let $r$ vary independently for each type of voter.

Calculating the approval vote outcome for every combination of $\left\{r_{1}, r_{2}\right.$, $\left.r_{3}, \ldots r_{n !-1}, r_{n !}\right\}$ would be an impossible task if we could not take advantage of convexity. ${ }^{7}$ Fortunately, the space of profiles is convex, the space of outcomes (the representation triangle) is convex and approval voting is a convex (linear) mapping from the space of profiles to outcome space. A convex mapping from a convex domain creates a convex image. A vertex in profile space will therefore map to a vertex of the AV outcomes in outcome space. The space bounded by the convex hull of the outcome vertices is the set of all possible approval vote outcomes (for a given profile). A simple example will illustrate. Suppose all voters are of Type 1. To find all possible $\mathrm{AV}$ outcomes we find the AV outcome where every voter casts a top-one ballot. We then find the AV outcome where every voter casts a top-two ballot. The line connecting these outcomes gives the AV outcome for every other proportion. Suppose all voters are of Types 1 and 2. We now have four profile vertices to consider, as shown in Table 1 . By connecting the outcomes associated with each profile vertex we find the space of possible AV outcomes.

When there are $n$ candidates there are $n$ ! types of voters and each type can cast a top-one or top-two ballot so in general there are $2^{n !}$ possible

Table 1. Possible Ballots when all Voters are of Types One or Two

\begin{tabular}{|l|l|}
\hline$r_{1}=0, r_{2}=0$ & $r_{1}=0, r_{2}=1$ \\
\hline$r_{1}=1, r_{2}=0$ & $r_{1}=1, r_{2}=1$ \\
\hline
\end{tabular}

7. Suppose we take two points within a space and connect those points with a straight line. If every point along the connecting line is also within the space, and this is true no matter which points we pick, the space is said to be convex. A circle, for example, is convex but a horseshoe is not. Convexity is a useful property because it lets us describe a space very compactly. A square contains an infinite number of points but since the square is convex we can describe all of these points by referring to the coordinates of the square's vertices.

In the text we make use of an important theorem which says that if a convex space is linearly mapped (transformed) into another convex space the resulting image will be convex. The theorem implies that vertices in input space will map to vertices in output space. Thus, if a square is linearly mapped we do not need to map each of the infinite number of points to find the new space. Instead we find the new space merely by mapping the vertices of the square and connecting the resulting image vertices. In the text these ideas are applied to voting.

More precise definitions of convexity can be found in any mathematics text. Saari (1994) gives a useful discussion of convexity in the context of voting models. 
ballot vertices. Thus, to find all possible AV outcomes, when there are four candidates we need to compute the outcome for each of the $16,777,000$ ballot vertices and then find and plot the convex hull of the AV outcome vertices. Even with a rather fast PC, calculating this many quadruples and storing them is not feasible. Luckily we will be able to reduce the size of the problem by eliminating some possible rankings. Few people who ranked Lincoln first, for example, are likely to have the pro-slavery candidate, Breckinridge, ranked second.

Approval voting has been adopted for use by the US National Academy of the Sciences, the Mathematical Association of America, the Institution of Electronics Engineers (a 300,000-member organization) and many other groups and societies in the United States (Brams and Nagel, 1991; Merrill, 1988). Although it has not yet been used in US elections, approval voting has been used for referenda in Oregon and a bill permitting the use of approval voting in public elections has passed the North Dakota senate (Weber, 1995). A modified form of approval voting is used to select the Secretary General of the United Nations. Approval voting has also been put forward as an alternative solution to the problem of minority vote dilution in the United States (the current solution being racial gerrymandering). The increasing use of approval voting in the US indicates that an investigation of its properties is of more than theoretical interest.

\section{The Election in Historical Perspective}

Present-day observers of presidential politics would undoubtedly find many of the characteristics of the 1860 election quite unusual. Perhaps the key element to the whole election process was that there were no federal or state-printed ballots. Instead, political parties printed their own ballots which were distributed at the polls and used for voting. As a result, to run for office, all an independent candidate needed was a printing press. Low barriers to entry allowed the Constitutional Union party to run a candidate for president in any state it desired, and it also allowed disaffected Democrats to break away from Douglas and nominate Breckinridge as a second Democratic candidate. ${ }^{8}$

The Democrats met to choose their presidential candidate in Charleston. Already divided, the party basically disintegrated over their position on

\footnotetext{
8. This section draws upon biographies of Bell, Douglas and Breckinridge by Parks (1950), Wells (1971), and Davis (1974) respectively, as well as on general histories of the 1860 election and the civil war by Boritt (1996), Fite (1967), Luthin (1944), and McPherson (1988). Statistics on the 1860 election can be found in Petersen (1981).
} 
slavery. The delegates supporting Stephen Douglas of Illinois wanted to include the doctrine of 'popular sovereignty' in the platform. Popular sovereignty let territories enter the Union as free or slave states depending on the results of local referenda. The delegates supporting John Breckinridge of Kentucky feared that such voting would lead to a majority of free states in the Union and a Congress which would refuse to enforce the Dred Scott decision. Breckinridge supporters wanted a pro-slavery plank. After days of debate, the Douglas forces won the platform fight by a vote of 165 to 138, which divided almost entirely on sectional grounds. Despite winning the platform, Douglas didn't have the two-thirds of the total vote necessary to win the nomination. After 57 ballots, the delegates adjourned and agreed to meet six weeks later in Baltimore. Time did not cool heads and in Baltimore most of the pro-slavery delegates eventually walked out of the convention and on their own nominated Breckinridge. Those who remained nominated Douglas. Thus, in 1860 two Democrats from different regions and with substantially different views ran for the presidency.

The Republicans held their convention in Chicago with William $\mathrm{H}$. Seward of New York being the pre-convention favorite to win the nomination. Seward, however, had angered many party members with statements which were construed as support for the radical-abolitionist John Brown who had been hanged less than a year earlier. Seward was also hurt by the taint of political corruption associated with New York. As a result, six other candidates, including Abraham Lincoln, arrived at the convention with some support. On the first ballot Seward received 173 votes to Lincoln's 102. Seward's 173 votes fell short of the 233 votes needed to carry the nomination. As candidates dropped out and new alliances were formed, Lincoln gained on the second ballot and obtained the nomination on the third. In some sense, Lincoln was the ideal candidate, especially in retrospect. Republicans, in order to win the election, needed to hold just about all of the free states. The key states that would swing the balance were Illinois and Indiana. Lincoln was perhaps the only person who could win these states, especially in the face of competition from Douglas. Lincoln had made few enemies, had made some friends campaigning for fellow Republicans, and was perceived all around as a man of integrity. Very few of the delegates had major reservations about Lincoln, and unlike the Democrats the Republicans emerged from the convention united.

In between the Democrat and Republican conventions, another group of delegates met in Baltimore to offer a fourth candidate, John Bell of Tennessee. The delegates were mostly elder statesmen of what was formerly the Whig party, who could not support Lincoln. Calling themselves the Constitutional Union party, their platform essentially ignored the slavery issue and maintained the supremacy of the Constitution. The Constitutional Unionists were well aware that they could not win the 
election but if they could win some of the border states and throw the election into the House of Representatives they might have enough power to swing the election to a candidate of their choosing.

\section{The Campaign}

Plurality rule and the existence of more than two candidates seem to have created a Republican victory. Of the four candidates, Lincoln's strategy was the clearest. The free states constituted 180 of the 303 electoral votes. Thus, to win the election, Lincoln needed victory in most of those states. Since New York had 35 electoral votes, victory there was paramount. Thus, the Lincoln forces spent all their efforts in the free states and didn't even campaign in ten southern states.

Breckinridge's and Bell's strategies are a bit murkier. Breckinridge's strength was in the South while appropriately enough the 'compromise' candidate, Bell, had strength in the border states. There weren't enough electoral votes in either or both of these areas, however, to guarantee any candidate, even a unanimously supported one, a victory. Two schools of thought prevail on the motives of Breckinridge and Bell. First, each was counting on Douglas to win enough Northern states to force the election into the House of Representatives, where they had a much better chance of winning. Second, some have suggested that Breckinridge's main goal was to see that Lincoln rather than Douglas was elected. While some of this was due to the antipathy between Douglas and Breckinridge, Southern radicals favored this strategy to further their goal of Southern secession.

Douglas' strategy was more complicated. It was clear, going into the election, that he had substantial strength in the north and northwest (Illinois, Indiana, Wisconsin, Iowa, etc.). Douglas also thought that he had a very good chance to win Missouri, Arkansas, Louisiana, Texas, Alabama and Georgia. So, unlike the other candidates, Douglas ran a national campaign. ${ }^{9}$ Douglas, however, had seriously miscalculated his strength in the South. As a result, instead of concentrating on the border states, the northwest, a few northern states and New York and New Jersey, he spent

\footnotetext{
9. In our analysis of the election we will assume that each voter has access to a ballot which names each of the candidates. In the actual election, no candidate had elector slates in all states. A more extensive analysis, but one beyond the scope of this paper, would analyze candidate strategies under different electoral systems. Had voters been able to indicate second and third rankings, for example, the incentive to campaign nationally would have increased. The extreme geographic divisions evident in 1860 were thus not solely due to fundamental divisions in society (although these clearly played the primary role) but also to the nature of the electoral system.
} 
much of his time campaigning in the South and New England, states which as it turned out, he had little or no chance of winning. ${ }^{10}$

By the time the election came, the results were almost an anticlimax. Since several state elections were held earlier in the summer and fall, the lay of the land was fairly clear. State elections in August showed that Breckinridge would be unable to sweep the South. September elections in Vermont and Maine indicated overwhelming strength for Lincoln in New England. Republican victories in October elections in Pennsylvania, Ohio and Indiana, however, really told the tale. ${ }^{11}$ At that point, the candidates opposing Lincoln realized that the only way that he could be defeated would be to form fusion tickets in New Jersey and New York. There was even a suggestion of having all three candidates withdraw in these states and support some as yet unnamed candidate (as we discuss further below). In the end, however, the fusion ticket only had a modicum of success in New Jersey.

In the final tally Lincoln won 39.79 percent of the popular vote and 180 of the 303 electoral college votes. Douglas received the second-largest share of the popular vote, 29.4 percent, but only 12 electoral votes. Finally, although Breckinridge won 72 of the 120 slave-state electoral votes, Douglas and Bell combined received more popular votes in the South than did Breckinridge.

\section{The Analysis}

To understand the impact of the electoral system on the outcome we need to know the number of voters who held each possible ranking. Even today polls rarely report this type of information, and in 1860 there were few public opinion polls of any type. To remedy this lack of data we carried out a survey among a number of historians, all of whom had written on the election of 1860 or more generally on the politics of the pre-civil war era. Although there are 24 possible rankings of the candidates, we simplified our survey by eliminating a number of implausible rankings. We assumed, for example, that few Lincoln voters would rank the pro-slavery candidate, Breckinridge, second or even third. After eliminating implausible rankings,

10. It is interesting to note that Douglas broke with tradition by campaigning for himself. Prior to this election, presidential candidates were generally unseen during the campaign process. Instead their organizations and their associated newspapers were responsible for the campaigning. None of the other candidates campaigned for themselves in 1860.

11. Upon hearing news of Lincoln's victories in Pennsylvania, Ohio, and Indiana, Douglas said to his private secretary 'Mr. Lincoln is the next president. We must try to save the union. I will go South' (McPherson, 1988: 231). Douglas warned southerners that a civil war would follow any attempt at secession. 
our survey contained 14 categories and we asked historians to estimate the percentage of each candidate's voters in each category. We also left space for the addition of any category not included by us which historians might have thought was important. (This option was not used in any of our completed surveys.)

After eliminating incomplete surveys, we had 13 estimates of the entire 1860 voter ranking, each from a prominent historian. ${ }^{12}$ We use the mean of the survey rankings and Riker's (1982) published estimates as our estimates of the voter profile. Differences between Riker's profile and the Mean Historian Profile are interesting in themselves and also as an indication of the effect of different profiles on electoral outcomes. Letting $R$ denote Breckinridge and $L, D$, and $B$ denote Lincoln, Douglas and Bell respectively Riker's profile is shown in Figure 5.

$$
\begin{gathered}
\left\{0^{L D R B}, 9.59^{L D B R}, 0^{L R D B}, 0^{L R B D}, 30.2^{L B D R}, 0^{L B R D}\right\} \\
\left\{1.79^{D L R B}, 6.76^{D L B R}, 3.67^{D R L B}, 10.37^{D R B L}, 6.79^{D B L R}, 0^{D B R L}\right\} \\
\left\{0^{R L D B}, 0^{R L B D}, 2.24^{R D L B}, 7.08^{R D B L}, 0^{R B L D}, 8.88^{R B L D}\right\} \\
\left\{5.77^{B L D R}, 0^{B L R D}, 2.44^{B D L R}, 0.6^{B D R L}, .66^{B R L D}, 3.12^{B R D L}\right\}
\end{gathered}
$$

Figure 5. Riker's Profile: The 1860 Election

The notation $6.79^{D B L R}$, for example, indicates that according to Riker 6.79 percent of all voters held the ranking Douglas $>$ Bell $>$ Lincoln $>$ Breckinridge. ${ }^{13}$ The Mean Historian Profile (MHP) is shown in Figure 6.

$$
\begin{gathered}
\left\{0^{L D R B}, 21.17^{L D B R}, 0^{L R D B}, 0^{L R B D}, 18.61^{L B D R}, 0^{L B R D}\right\} \\
\left\{0.11^{D L R B}, 8.04^{D L B R}, 0.22^{D R L B}, 4.87^{D R B L}, 8.59^{D B L R}, 7.53^{D B R L}\right\} \\
\left\{0^{R L D B}, 0^{R L B D}, .13^{R D L B}, 6.87^{R D B L}, 0^{R B L D}, 11.19^{R B L D}\right\} \\
\left\{1.70^{B L D R}, 0^{B L R D}, 4.48^{B D L R}, 3.81^{B D R L}, 0.04^{B R L D}, 2.56^{B R D L}\right\}
\end{gathered}
$$

Figure 6. Mean Historian Profile: The 1860 Election

Of those voters who ranked Lincoln first, how many had Bell ranked second and how many had Douglas ranked second? It is on this question

12. Using a computer search for authors of books or articles on the civil war era, supplemented with names listed under civil war historians in the Directory of History Departments and Organizations in the United States and Canada (American Historical Association, 1997), we created a list of 100 historians to whom we mailed surveys. We received 21 responses in total; in eight cases the responses were incomplete or the historians indicated that they did not have the requisite knowledge, leaving thirteen responses which were used to create the Mean Historian Profile. It's difficult to create a meaningful measure of variance in the historians' responses, which is one reason we have presented results from two profiles. Comparing results from Riker's profile and the Mean Historian Profile gives some indication of how profile variance translates into outcome variance.

13. We have converted Riker's estimates of total voters into percentages. Exact numbers were used in calculations; the numbers presented may not sum exactly to 100 percent, due to rounding. 
that Riker's profile and the MHP disagree most. Riker has most Lincoln voters ranking Bell second whereas the historians have a majority of Lincoln voters ranking Douglas second, although the historians have a more even division than does Riker. As we shall see, this distinction determines whether Bell could have won the election under a different voting system.

\section{What Would have Happened under Different Positional Voting Systems?}

Figure 7 shows the vote outcome under all possible positional voting schemes. Bell's vote share is suppressed and is equal to one minus the vote share of the other candidates. The plurality rule outcome $\{39.79,29.39$, 18.2,12.6\} denoting $L>D>R>B$ is indicated on the left of the diagram. Beginning at the plurality rule outcome, suppose we move along the bottom edge of the positional voting plane. What happens? A little less than one-third of the way along the edge we cross the Breckinridge $=$ Bell line so that Bell moves ahead of Breckinridge, giving the outcome $L>D>B>R$. (The Breckinridge = Bell 'line' is actually the set of points where the Breckinridge $=$ Bell plane (shown in Figure 3) intersects the positional vote outcome plane.) As we continue along this edge we cross the Lincoln $=$ Douglas line and the outcome becomes $D>L>B>R$. Continuing further we cross the Lincoln $=$ Bell line, which puts Lincoln into third place. Thus, if instead of voting for their favorite candidate (plurality rule), voters had voted against their least favorite candidate (anti-

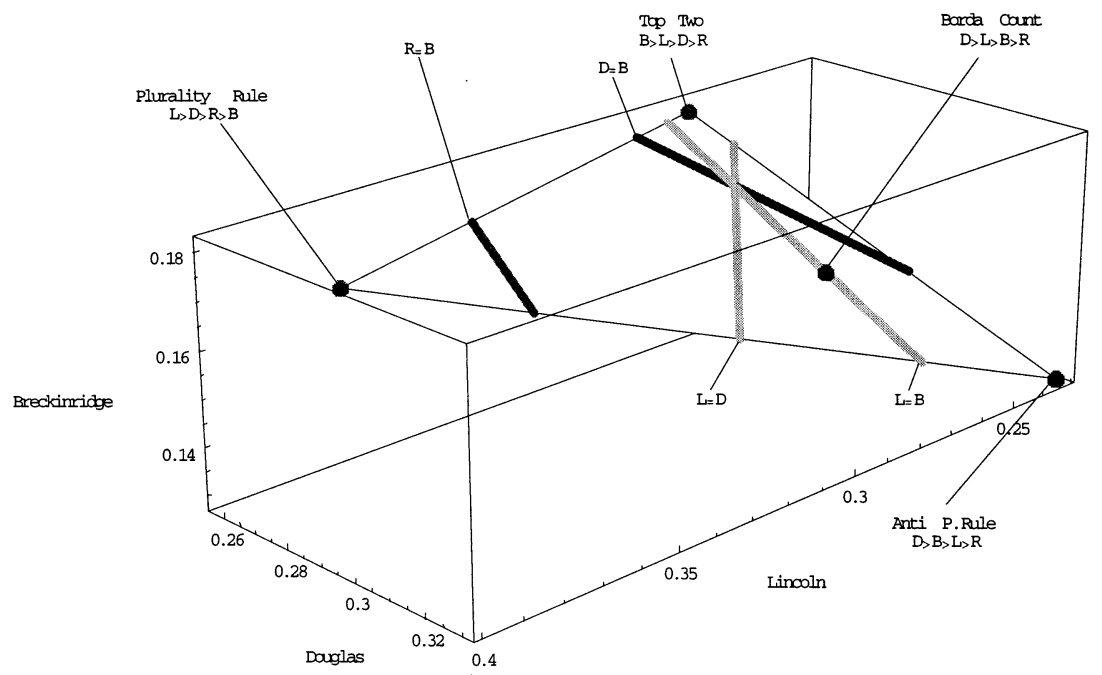

Figure 7. The Positional Vote Plane using Riker's Profile 
plurality rule) Douglas would easily have beaten Lincoln who would have come in third, the entire outcome being $D>B>L>R$. Indeed Douglas would have beaten Lincoln under any voting system which gave significant weight to candidates ranked second and third. Douglas would have beaten Lincoln and won the election, for example, under the Borda Count, which gives weights of $\left\{\frac{1}{2}, \frac{1}{3}, \frac{1}{6}\right\}$ to candidates placed first, second and third respectively. It is difficult to justify counting second and third preferences for nothing; Douglas therefore was a very strong contender for 'best' candidate in the 1860 election.

Now consider what happens if we move from the anti-plurality rule outcome upwards toward the top-two outcome. The top-two outcome has weights $\left\{\frac{1}{2}, \frac{1}{2}, 0\right\}$ so as we move upwards we are placing less weight on thirdranked preferences. Moving from the anti-plurality rule outcome to the top-two outcome causes us to cross the Douglas $=$ Bell line so we move from $D>B>L>R$ to $B>D>L>R$. At the time, Bell's candidacy was ridiculed by most observers as the last gasp of a party of old men. The plurality rule outcome supported the ridiculers as Bell came in last. Yet, if Riker's profile is close to correct, Bell was a much stronger candidate than he appeared. Few voters ranked Bell first but many ranked him second or third, enough so that the 'old man' might have won the election under a different voting system.

Figure 8 shows the positional vote plane when the Mean Historian Profile is used in place of Riker's profile. The MHP gives fewer secondplace votes to Bell and as a result Bell cannot win the election under any

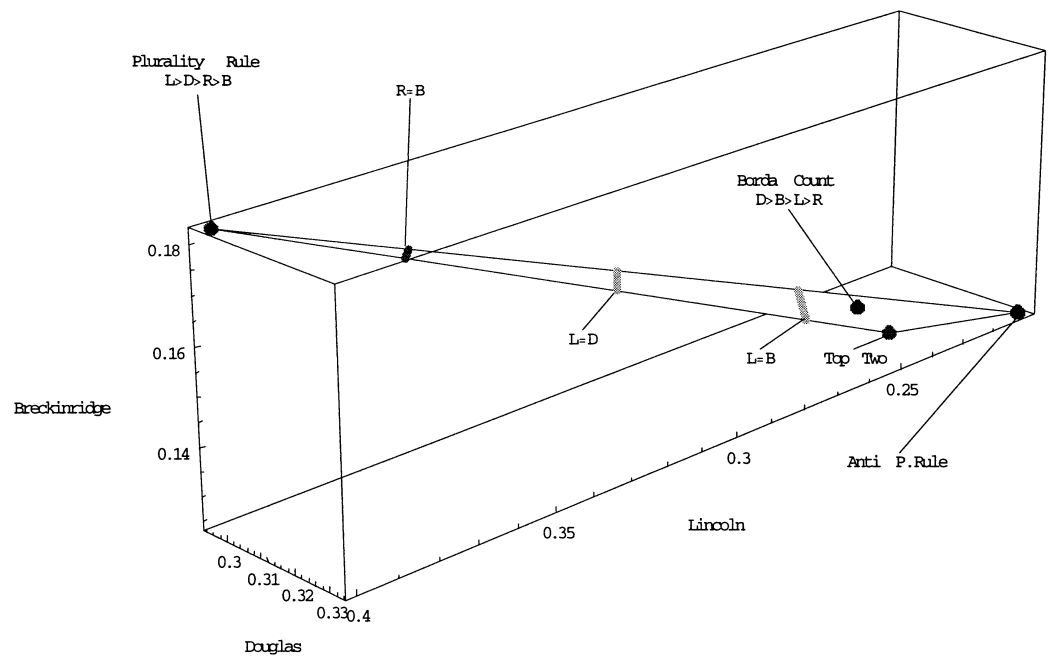

Figure 8. The Positional Vote Plane under the Mean Historian Profile 
positional voting system. What Bell loses is mostly gained by Douglas so that Douglas wins (not just beats Lincoln) under any positional voting system which gives significant weight to second- or second- and thirdranked preferences. Douglas would have won, for example, under the voting system $\{.7, .3,0\}$ which gives more than twice the weight to first-place candidates than it does to second-place candidates.

\section{What Would have Happened under Approval Voting?}

The Mean Historian Profile contains 16 non-zero elements and thus an implied $3^{16}=43,046,721$ approval-vote ballot combinations! Time and computational constraints made calculating all of these ballots not feasible. To make the problem more manageable we constrained the smallest five voter types (Types 7, 9, 15, 19, and 23) to casting a single top-one ballot. The five constrained types account for only 2.22 percent of the population and the remaining 97.78 percent, consisting of 11 types, were allowed to cast any of the three possible ballots. We were thus required to calculate a comparatively few $3^{11}=177,147$ different ballots. It is highly unlikely that this computational simplification caused any appreciable difference in the final results. Similarly, Riker's profile has 15 non-zero elements and we constrained the smallest four voter types (Types 7, 15, 22 and 23), comprising 5.29 percent of the population, to casting a single top-one ballot. For each profile we therefore had a set of 177,147 possible outcomes for which we calculated the convex hull. Any point within the convex hull of the 177,147 outcomes generated by each possible ballot is a possible outcome under approval voting.

Figure 9 shows the space of possible approval vote outcomes using the
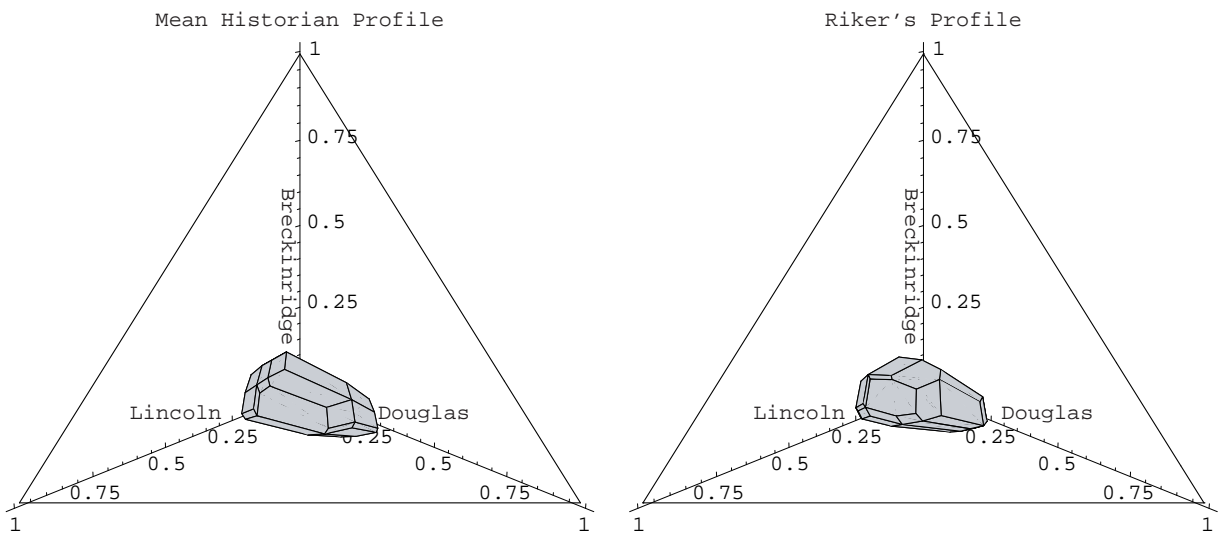

Figure 9. All Possible Approval Vote Outcomes 1860 


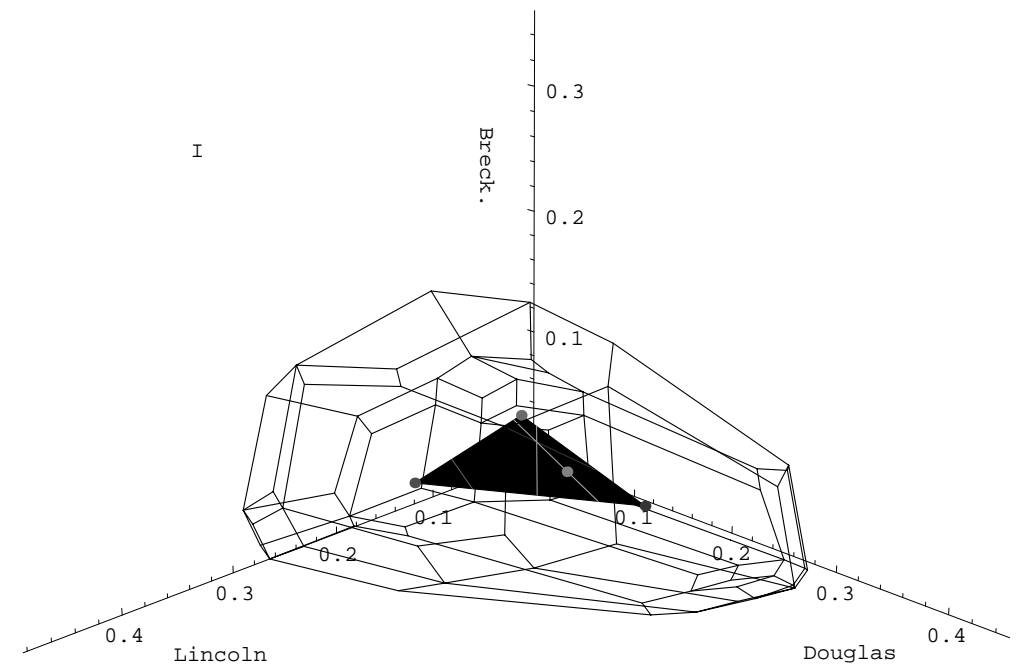

Figure 10. Riker's Profile: Outcomes under every Positional Vote System and every Possible AV Outcome

MHP and Riker's profile. The spaces are of similar size and shape although under the MHP Douglas tends to do somewhat better than under Riker's profile. Notice that both spaces are quite large. A single profile generates a single outcome under positional voting systems. Under approval voting, however, a single profile generates an entire space of outcomes. The indeterminateness of approval voting is one of its weaknesses. ${ }^{14}$ Although both profiles exhibit considerable indeterminateness under AV, the indeterminateness is not complete - not every possible outcome can occur. Consider the point $\{.25, .25, .25\}$. At this point all four candidates are tied. A necessary and sufficient condition for complete indeterminateness is that the space of AV outcomes shall enclose this point. But by inspection, neither AV space encloses this point.

How does the space of approval vote outcomes compare with the space of outcomes generated by all positional voting systems? Figure 10 shows, using Riker's profile, the outcome under every positional vote system and every possible AV outcome (the figure using the MHP is similar). The AV outcomes enclose the positional vote outcomes, as we know must be the

14. On indeterminateness under AV see the debate between Saari and Van Newenhizen (1988a, b), and Brams et al. (1988). Tabarrok (unpublished working paper, 1997), contrary to Brams et al. (1988), shows that AV cannot be defended on the grounds that it uses cardinal in addition to ordinal information to choose outcomes. 
case from Theorem 1. Furthermore, recall that the lines on the positional vote plane are points of intersection between the surface and the planes which separate the 24 ranking regions. Since the AV space is so much larger than the positional vote plane it is likely that the AV space enters into more ranking regions than does the positional plane. We show that this is indeed the case in the next diagram (Figure 11).

The additional rankings possible under AV can be seen in Figure 11. The figure is less imposing than it initially looks. The plane $L=D$ indicates the outcomes where Lincoln and Douglas are tied. In Figure 10 this plane split the figure vertically down the middle; thus, we have now shifted our viewpoint to the I indicated in Figure 10. The plurality rule outcome is hidden in Figure 11 but its position is indicated by: (1) $L>D>R>B$. Moving vertically we pass over the $R=D$ plane and Breckinridge moves ahead of Douglas; (2) $L>R>D>B$ (this outcome was not possible under any positional vote system but is possible under AV). Passing over the $B=$ $D$ plane Douglas comes in last and we enter the ranking region (3) $L>R>B>D$. Bell beats Breckinridge below the $R=B$ plane and the next ranking region is thus (4) $L>B>R>D$. Finally, Bell beats Lincoln to the left of the $B=L$ plane and we have region (5) $B>L>R>D$. In addition to the rankings possible under the class of positional vote systems, we

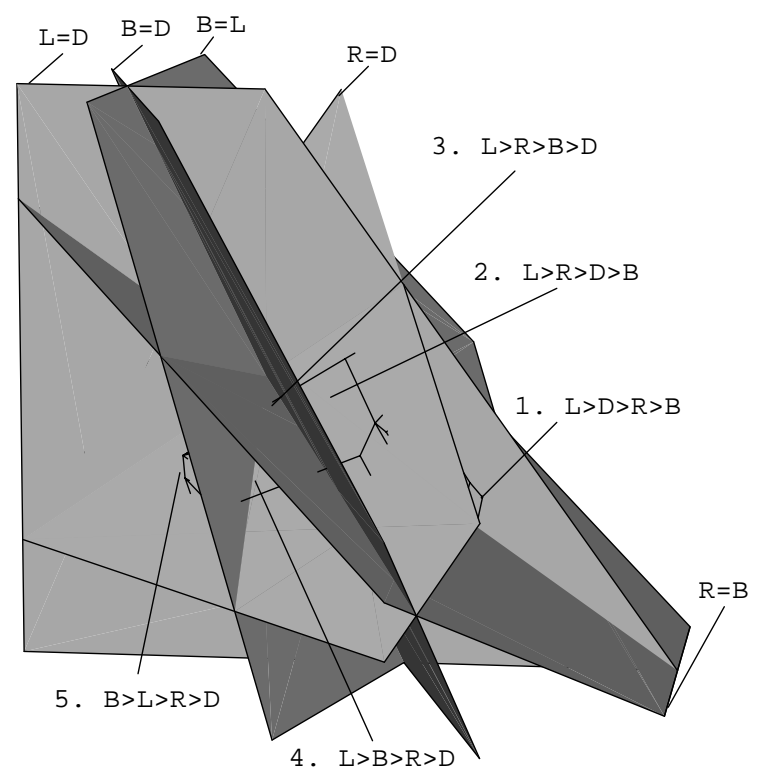

Figure 11. The AV Space Intersects more Ranking Regions than does the Positional Vote Plane 
conclude that $\mathrm{AV}$ is also consistent with five other rankings. ${ }^{15} \mathrm{~A}$ similar diagram exists for the Mean Historian Profile. Thus, we see that much more is possible under approval voting than under the entire class of positional voting systems.

Estimating intensities of preference is even more difficult than estimating rankings. We have not, therefore, tried to estimate, for example, how many Douglas voters would have 'approved' of Breckinridge. Readers, however, can use their own estimates and Figure 10 to calculate roughly what would have happened. The point furthest to the left on the positional voting plane is the plurality rule outcome - this is what would have happened under approval voting if all voters had voted for their top-ranked candidate only. Lincoln would have won an even greater percentage of votes (moving the outcome outwards along the Lincoln axis) if voters who ranked Lincoln second had cast top-two ballots while all others had cast top-one ballots. On the other hand, if voters who ranked Douglas second had cast top-two ballots while all others cast top-one ballots, the outcome would have moved outwards along the Douglas axis. Similarly, note that the top-two outcome on the positional plane (the back corner outcome, labeled in Figure 7) is what would have happened under AV if every voter had cast top-two ballots. If every voter had cast top-two ballots except voters who ranked Breckinridge third and who cast top-three ballots, the outcome would have moved upwards and toward the back along the Breckinridge axis.

\section{What Would have Happened under Pairwise Voting?}

Figure 12 summarizes what would have happened if the candidates had been paired one against the other in a series of votes. The arrows indicate 'is preferred to' in a pairwise contest and the numbers indicate by what percentage of the vote candidate $A$ would have beaten candidate $B$. Douglas was the Condorcet winner, given the mean historian profile. ${ }^{16}$ Douglas would have beaten Lincoln by a large 16.9 percent of the vote and he would have beaten Breckinridge by a whopping 58.3 percent. Douglas's closest competitor is Bell whom he would have beaten by 15.1 percent. Bell beats Lincoln but only by the slimmest of percentages (less than 1 percent). Breckinridge loses to all other candidates and is thus the Condorcet loser.

As is well known, pairwise voting can lead to intransitive outcomes and one such outcome occurs given Riker's profile of voters. Any race between

\footnotetext{
15. These additional outcomes consistent with AV but not positional voting are: (1) $L>D>R>B$; (2) $L>R>D>B$; (3) $L>R>B>D$; (4) $L>B>R>D$; and (5) $B>L>R>D$.

16. A Condorcet winner is a candidate who beats all other candidates in a series of pairwise votes.
} 


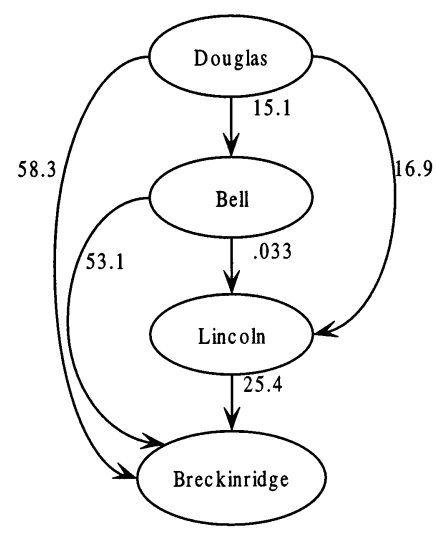

Mean Historian Profile

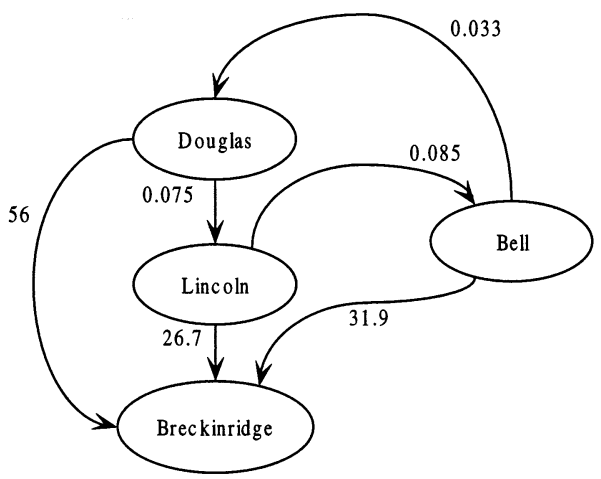

Riker's Profile

Figure 12. Pairwise Voting Outcomes: The 1860 Election

Douglas, Lincoln and Bell is a dead heat with the winner in each race beating the loser by a less than 1 percent margin. As the profile stands, Lincoln $>$ Bell, Bell $>$ Douglas but Douglas $>$ Lincoln. Breckinridge is once again the Condorcet loser (which is significant given that he beat Bell in the plurality rule election).

Under either profile, Douglas is preferred to Lincoln. Thus, had neither Breckinridge nor Bell stood for election, Douglas, not Lincoln, would have won, potentially by a large margin. ${ }^{17}$ In the next section we examine what would have happened if either Breckinridge or Bell had dropped out.

\section{What would have happened if either Bell or Breckinridge had dropped out?}

If a candidate drops out of a plurality rule election, that candidate's voters shift their votes to their second-ranked candidate and little else occurs. Under other positional vote systems the situation is more complicated, because the distribution of second, third, and $n$ th-ranked candidates changes when a candidate drops out. As an extreme example, if a candidate who is ranked first by no-one drops out of a plurality rule election there is no change in the outcome. If the same candidate drops out of an election

17. This conclusion is altered when we take into account the electoral college (see Appendix). 
under any another positional vote system or under approval voting the outcome may change considerably. To understand what would have happened had a candidate dropped out of the 1860 election we need to know the entire voter profile.

There is a good possibility that Breckinridge would have withdrawn from the race under slightly different circumstances. In fact, Breckinridge's biographer, William Davis (1974), argues that he entered the race planning to withdraw. Initially, Breckinridge didn't want the nomination and had decided to refuse it when Jefferson Davis intervened. Davis had calculated that Douglas and Bell would split the vote, thus ensuring a Lincoln victory. Neither Douglas nor Bell would resign in favor of the other but they might be convinced to withdraw in favor of a yet unnamed compromise candidate. To put more pressure on them, Breckinridge was encouraged to accept the nomination in the hopes that his willingness to withdraw as part of a trio would encourage the others to do likewise. Unfortunately, Douglas and perhaps Bell still refused to withdraw. And, having accepted the nomination, Breckinridge felt honor bound not to withdraw unilaterally. Thus, we have the odd circumstance that if Breckinridge had realized the futility of the plan or if he had felt less honor bound, there would have been only one Democratic candidate and the election could have turned out quite differently, as we shall show.

Breckinridge represented an extreme pole in the election and his absence causes considerable shifting in the balance of power. When Breckinridge drops out Douglas gains in power but so does Bell, pulling the election closer to the all tie-point. Figure 13 tells the story.

Under both the Mean Historian Profile and Riker's profile, Lincoln wins under plurality rule (PR) but in a dead heat with Douglas (note how close
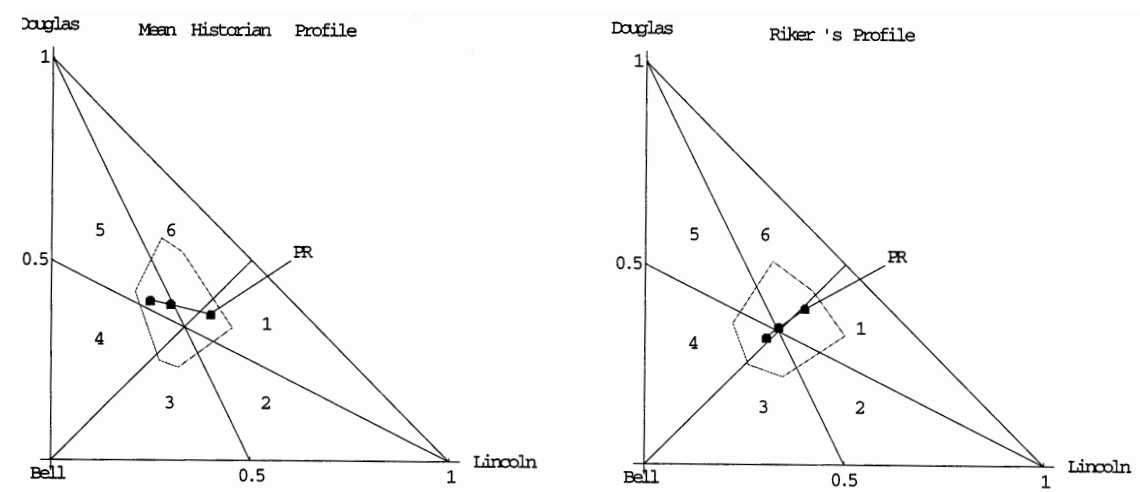

Figure 13. All Positional and Approval Vote Outcomes if Breckinridge Withdraws $(\mathrm{PR}=$ plurality rule $)$ 
the PR outcome is to Region 6). Under virtually any other positional system, Douglas wins under the MHP and Douglas or Bell wins under Riker's profile. The fragility of the election is illustrated under Riker's profile by the procedure line, which enters regions $1,6,5$, and 4 . Including ties, Riker's profile generates seven different rankings (the maximum possible)! Under the Mean Historian Profile, five different rankings are possible. Furthermore, approval voting is completely indeterminate under both profiles: depending on which ballots are cast, any candidate can win the election under AV.

Breckinridge's candidacy is thus the linchpin of the election. Oddly enough from an ideological standpoint, Breckinridge greatly benefitted Lincoln, because Breckinridge drew support from all candidates except Lincoln.

Bell never indicated any willingness to withdraw and because he drew support from all three of the remaining candidates his withdrawal would not have significantly affected the balance of power; it is worth examining, however, as a contrast to that of Breckinridge's. Under both the MHP and Riker's profile, Lincoln's share of the vote would have increased, although more under the latter than the former. In the plurality rule election, Douglas comes in second and Breckinridge third. As was the case with the four-candidate election, Douglas wins under the Borda Count and a large number of alternative positional vote systems. Under approval voting either Douglas or Lincoln may win, but Breckinridge cannot win under any positional vote system or under approval voting. This information is summarized in Figure 14. Note that an outcome in Region 1 has the ranking $L>D>R$, Region 2 has the ranking $L>R>D$ and Region 6 the ranking $D>L>R$.
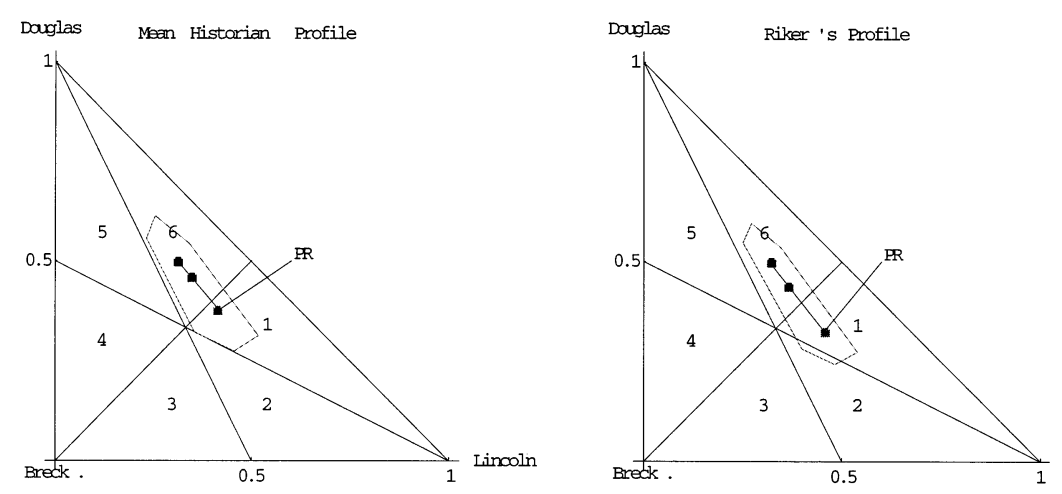

Figure 14. All Positional and all Approval Vote Outcomes if Bell Withdraws $(\mathrm{PR}=$ plurality rule $)$ 


\section{Strategic Voting}

Up to this point we have assumed that voters vote sincerely. The assumption of sincere voting has been motivated by two considerations. First, our primary interest in studying the election of 1860 is to ask 'Which candidates in 1860 best represented the preferences of the voters?' One way of answering this question is to hold preferences constant and vary the voting system to discover which candidates are robustly supported. If voters do vote sincerely, then, as a by-product, our normative analysis answers the question, 'What would have happened in 1860 had the voting system been different?' Thus, the assumption of sincerity is necessary for normative analysis and sheds light on positive analysis to the extent that voters vote sincerely.

A second reason for the sincerity assumption is that an analysis of strategic voting requires much more information than an analysis of sincere voting. In particular, to figure out the election outcome under strategic voting requires us to be able to assign cardinal preferences to each voter. Furthermore, strategic voting requires each voter to have an expectation of the outcome - which means that each voter must predict how every other voter will vote. An example will illustrate some of the problems involved. Consider a voter with the preferences $B>D>L>R$ and assume the voting system is positional, for example the Borda Count. If the voter believes that Lincoln and Bell are the front runners, one strategy would be to vote the insincere ballot $B>D>R>L$. This ballot reduces the number of Lincoln votes and helps Bell to win. On the other hand, if the voter believes that Lincoln and Douglas are the front runners, then they might switch to the insincere ballot $D>B>R>L$. Which of these strategies is optimal depends on the cardinal utilities assigned to each candidate and on the probabilities the voter assigns to a win by each of the candidates. Furthermore, in a fully rational equilibrium the win probabilities must be consistent with the strategies of the voters (Myerson and Weber, 1993). Computing a fully rational equilibrium of this sort is beyond the scope of this paper. ${ }^{18}$

With the above qualifications in mind we mention a few of the possible strategic votes. We know from our discussion of pairwise voting that Douglas would have beaten Lincoln in pairwise voting. It follows that if every voter who ranked Douglas above Lincoln had ranked Douglas first and Lincoln last then Lincoln would have lost under any positional voting system. This strategy would have resulted in a Douglas win under most systems but potentially not all; Bell or Breckinridge might have won under

18. It is even more difficult to analyze strategic voting under approval voting because under approval voting there are many more ballots which the voter might find it rational to cast under various circumstances. 
a voting system which weighted second- and third-place candidates heavily. More realistically, if Lincoln and Douglas were thought to be the front runners, then some Bell and Breckinridge voters might have switched. The historians' profile has a majority of Breckinridge voters preferring Lincoln to Douglas and almost all Bell voters preferring Douglas to Lincoln. Since there are more Breckinridge voters than Bell voters, the edge is given to Lincoln. Riker's profile, however, gives the opposite rankings and thus the opposite conclusion! Moreover, if Breckinridge voters had regarded Douglas and Lincoln as almost equally bad, while Bell voters had regarded Douglas as quite superior to Lincoln, more Bell voters than Breckinridge voters might have switched, despite the fact that there were more Breckinridge voters in total. The historical data do not provide the detailed information which is needed to analyze strategic voting equilibria. Tabarrok (1998), however, discusses the Mathematica code which was used to generate the diagrams and tables used in this paper. Using this code and Mathematica, readers may explore their own intuitions about strategic voting and its effect on the election of 1860.

\section{Conclusions}

The new graphical techniques illustrated in this paper allow us to see at a glance the effect of electoral systems in a way not previously possible. There are an infinite number of positional voting systems and the outcome under each of these can be shown in a single figure. All possible approval vote outcomes can be seen and comparisons made with other systems. The techniques used here are quite general and can also be used to analyze other voting systems like cumulative voting and run-offs. ${ }^{19}$

Under a different voting system Stephen Douglas could easily have won the election of 1860. Although Lincoln had a strong candidacy, Douglas does better when more information is used to determine the outcome, rather than less, as under plurality rule. It is even possible that John Bell would have won in 1860 with a voting system which was heavily weighted toward second- and third-placed candidates or with approval voting. John Breckinridge, the pro-slavery candidate, could not have won in 1860 under any of the voting systems we have examined. Nevertheless his candidacy was the linchpin of the entire election. Had Breckinridge dropped out, Douglas and Lincoln would have been in a dead heat under plurality rule, Douglas or Bell could have won under other positional vote systems and any candidate could have won under approval voting.

19. Saari (1994) shows how to analyze run-offs. Tabarrok (unpublished working paper, 1997) has analyzed cumulative voting. 


\section{APPENDIX: THE ELECTORAL COLLEGE}

As is well known, presidential elections in the United States are actually decided not by popular vote but by the electoral college. Each state is assigned electoral college votes equal to that state's number of senators and representatives. Electoral college votes are thus assigned roughly according to population although there is a bias favoring small states since each state has two senators anyway, regardless of size. The states have sole discretion about how electors to the electoral college are appointed. Since the 1830 s nearly every state has required that all of a state's electors be appointed according to the winner of that state's popular vote. ${ }^{20}$ To win the election outright, a candidate must win a majority of electoral votes. In the event that no candidate wins a majority of votes in the electoral college, the election is thrown to the House of Representatives where each state receives one vote and the majority winner becomes president. If the election is thrown to the House it is unclear whether this is the incoming or outgoing House. When the election went to the House in 1824 the outgoing (old) House chose the new president. ${ }^{21}$

As currently constituted, the popular vote winner receives all of a state's electoral college votes - this is sometimes called the unit-vote rule. At the other pole, electoral college votes could be allocated in proportion to the popular vote. Lincoln had a majority of electoral college votes under the unit-vote rule and a plurality of popular votes. Thus, if the election were decided by a plurality of electoral votes (i.e. without the possible intervention of the House) Lincoln would have won, whether electoral votes within each state had been allocated under the unit rule or the proportional rule or any linear combination of these rules. Actually the electoral college made Lincoln even stronger than this analysis indicates. If all of the non-Lincoln votes had gone to a single candidate, Lincoln would still have commanded a majority of the electoral college and won under the unit rule (Sterling, 1981).

Since Lincoln did not receive a majority of the popular vote, however, we know that had the electoral college rule been more proportional the election would have been thrown to the House. What would have happened in the House?

Lincoln won 17 of the 33 states in terms of popular vote. Thus, Lincoln might have won had the House voted according to the popular vote. It is likely, however, that the outgoing, rather than the incoming, House would have voted for the presidency, in which case we have fewer grounds for thinking that Lincoln would have won. Furthermore, strategic considerations would surely play a larger role in the House vote than in the popular vote. Analyzing an election where the voters are lame-duck Members of the House with very complicated interests is probably not possible, given the information currently available. What we can say is, that should the election have made it to the House, the end result would have been quite unpredictable. This is perhaps why all four candidates were optimistic about their chances of winning the presidency, or at least determining the outcome.

20. Typically, each state party creates a slate of potential electors. The legislature then appoints as state electors the slate of the candidate who receives the most popular votes. Presently, the only exceptions to this winner-take-all rule are Nebraska and Maine. Regardless of the electoral rule, nothing in the Constitution or federal law (state laws differ) requires the electors to vote for the candidates for whom they are pledged to vote. In 1860, for example, four of the seven New Jersey electors voted for Lincoln despite the fact that Douglas won the popular vote. For a complete discussion of the electoral college see Berns (1992).

21. Some authorities suggest that the change in election timing which occurred with the Twentieth Amendment to the Constitution in 1933 implies that today the new House would have the power to choose the president. 


\section{REFERENCES}

Berns, Walter (ed.) (1992) After the People Vote: A Guide to the Electoral College. Washington, DC: AEI Press.

Boritt, Gabor S. (ed.) (1996) Why the Civil War Came. Oxford: Oxford University Press. Brams, Steven J. and Peter C. Fishburn (1983) Approval Voting. Boston, MA: Birkhauser.

Brams, Steven J., Peter C. Fishburn, and Samuel Merrill (1988) 'The Responsiveness of Approval Voting: Comments on Saari and Van Newenhizen', Public Choice 59: 121-31.

Brams, Steven J. and Samuel Merrill (1994) 'Would Ross Perot have won the 1992 Presidential Election under Approval Voting?' PS: Political Science and Politics 29 (March): 39-44.

Brams, S. J. and J. H. Nagel (1991) 'Approval Voting in Practice', Public Choice 71: 1-17.

Davis, W. C. (1874) Breckinridge: Statesman, Soldier, Symbol. Baton Rouge: LSU Press.

Fite, Emerson D. (1967) (first published 1911) The Presidential Campaign of 1860. Port Washington, NY: Kennikat Press.

Luthin, Reinhard H. (1944) The First Lincoln Campaign. Gloucester, MA: Peter Smith.

McPherson, James (1988) Battle Cry of Freedom: The Civil War Era. New York: Ballantine.

Merrill, Samuel (1988) Making Multicandidate Elections More Democratic. Princeton, NJ: Princeton University Press.

Myerson, Roger B. and Robert J. Weber (1993) 'A Theory of Voting Equilibria', American Political Science Review 87: 102-114.

Parks, Joseph H. (1950) John Bell of Tennessee. Baton Rouge: LSU Press.

Petersen, Svend (1981) A Statistical History of American Presidential Elections. Westport, CT: Greenwood Press.

Riker, W. H. (1982) Liberalism against Populism: A Confrontation between the Theory of Democracy and the Theory of Social Choice. San Francisco, CA: W. H. Freeman.

Saari, Donald G. (1994) Geometry of Voting. Berlin: Springer.

Saari, Donald G. and Jill Van Newenhizen (1988a) 'The Problem of Indeterminacy in Approval, Multiple, and Truncated Voting Systems', Public Choice 59: 101-120.

Saari, Donald G. and Jill Van Newenhizen (1988b) 'Is Approval Voting an Unmitigated Evil?: A Response to Brams, Fishburn, and Merrill', Public Choice 59: 133-47.

Sterling, Carleton (1981) 'Electoral College Misrepresentation: A Geometrical Analysis', Polity 13: 425-49.

Tabarrok, Alexander (1997) 'President Perot or Fundamentals of Voting Theory Illustrated with the 1992 Election', Unpublished Working Paper.

Tabarrok, Alexander (1998) 'Voting Theory with Representation Triangles and Cubes', Mathematica in Education and Research 7(3): 20-8.

Weber, R. J. (1995) 'Approval Voting', Journal of Economic Perspectives 9: 39-50.

Wells, Damon (1971) Stephen Douglas: The Last Years 1857-1861. Austin: University of Texas Press.

ALEXANDER TABARROK is Assistant Professor of Economics, and LEE SPECTOR is Associate Professor of Economics, at Ball State University. ADDRESS: Department of Economics, College of Business, Ball State University, Muncie, IN 47306, USA. [email: 00attabarrok@bsu.edu and001cspector@bsu.edu] 